\title{
Experimental Investigation to Study the Influence of Variation in Composition on Tribological Behavior and Impact Strength of Aluminium Alloy Al7068
}

\author{
Amardeepak Mahadikar ${ }^{1 *}$, Elliriki Mamatha ${ }^{2}$, Palur V. Krupakara ${ }^{3}$, Narayana B. Doddapattar ${ }^{4}$ \\ ${ }^{1}$ Department of Mechanical Engineering, Cambridge IT-NC, Bangalore 562110, India \\ ${ }^{2}$ Department of Mathematics, School of Science, GITAM University, Bangalore 561203, India \\ ${ }^{3}$ Department of Chemistry, Cambridge IT- NC, Bangalore 562110, India \\ ${ }^{4}$ Cambridge Institute of Technology-North Campus, Bangalore 562110, India
}

Corresponding Author Email: amardeepak.mech.nc@cambridge.edu.in

https://doi.org/10.18280/rcma.305-606

Received: 28 February 2020

Accepted: 16 November 2020

\section{Keywords:}

aluminium alloy, impact strength, magnesium, wear rate, zinc

\begin{abstract}
Aluminium alloys have a wide variety of applications in the industrial sector due to some unique characteristics like lightweight, high strength to weight ratio, corrosion resistance, good electrical conductivity, recyclability, ductility, and formability, etc. Due to this unique combination of properties, the applications of aluminium alloys continue to increase. The tribological behavior and impact strength were studied in this research work by conducting the wear and impact tests, varying the composition of two major alloying elements, Magnesium (Mg) and Zinc ( $\mathrm{Zn}$ ) of Al7068 aluminium alloy. The specimens were prepared as per ASTM standards for wear and impact tests, four compositions each for $\mathrm{Mg} \%$ varying b/w (2.2 to 3\%), and $\mathrm{Zn} \%$ varying b/w (7.3 to 8.3\%). The results of the wear test on the alloy Al7068 shows that the specimens with $3 \% \mathrm{Mg}$ and $7.6 \% \mathrm{Zn}$ compositions gives least wear rate at loads $2 \mathrm{~kg}$ and $3 \mathrm{~kg}$ respectively whereas the specimens with compositions of $2.75 \% \mathrm{Mg}$ and $7.3 \% \mathrm{Zn}$ give highest wear rate at a low load of $1 \mathrm{~kg}$. The impact test results indicate that specimens with compositions of $2.2 \%$ $\mathrm{Mg}$ and $7.6 \% \mathrm{Zn}$ of the alloy Al7068 give the highest impact strength which in turn improves its performance.
\end{abstract}

\section{INTRODUCTION}

Wear is a measure of progressive material loss as a result of relative motion between the operating surfaces in contact. In the industrial sector, wear is a paramount problem and its direct cost is estimated to vary between 1 and $4 \%$ of the net gross national product [1]. Huge amount of research is progressed to produce highly durable materials and vivid techniques are developed for wear reduction of tools and engineering components. The wear behavior of materials is evaluated by using Pin on disc wear test apparatus. Wear rate is a quantity generally used to measure the wear process and defined as the volume or mass of material that is removed in the unit time quantity or per unit sliding distance.

Charpy V-Notch (CVN) impact test is a mechanical method to evaluate the notch toughness value or impact strength of a given test specimen and named after one of its main theorists and developer Georges Charpy (1865-1945), a French engineer. This method is one of the popular, cost-effective, simpler and more reliable methods in the present world commonly used by regulatory and other codes for testing fracture critical structures such as bridges, pressure vessels and pipelines.

\section{LITERATURE REVIEW}

Choubey et al. [2] in their work studied the tribological characteristics of commercially used pure $(\mathrm{CP})$ metals such as Ti-6Al-4V, Ti, and Ti-5Al-2.5Fe in a simulated body fluid solution called Hank's solution. The results of their investigation revealed different wear mechanisms such as tribo-mechanical abrasion, cracking and transfer layer formation. They observed that the predominant wear mechanism was tribo-mechanical abrasion. Li et al. [3] studied the influence of heat treatment, surface modification and content effect on wear characteristics for the alloys Ti-Nb-Ta$\mathrm{Zr}$ and Ti-6Al-4V (TAV1). The authors in their work observed that the wear resistance improved by increasing the $\mathrm{Nb}$ content. The resistance to wear is enhanced by heat treatment for the alloys Ti-29Nb-13Ta-4.6Zr (TNZT1) due to oxide particle formation from $\mathrm{Nb}_{2} \mathrm{O}_{5}$.

Chiba et al. [4] studied the wear characteristics in high carbon content forged $\mathrm{Co}-\mathrm{Cr}$ and cast $\mathrm{Co}-\mathrm{Cr}$ alloys. The results indicated that wear resistance was considerably higher for forged $\mathrm{Co}-\mathrm{Cr}$ alloy than that of cast $\mathrm{Co}-\mathrm{Cr}$ alloy. The precipitation of carbide accounted for higher wear loss in the Co-Cr alloy.

Fischer et al. [5] investigated the wear characteristics of low-carbon Co-base alloy such as Co-Cr29-Mo, Cr-Ni-MnMo-N steel, Cr-Ni-Mo steels, and Ni-free Cr-Mn-Mo-N steel alloys in sliding wear. In this work, authors estimated wear characteristics in sliding wear by using the tests such as torsional fatigue and pin-on-disk tribometer followed by electron microscopy. The results indicated that wear behavior exhibited by Ni-free Cr-Mn-Mo-N steel alloys was superior to 
Cr-Ni-Mo steels. Xu et al. [6] examined the wear resistance of the alloys Ti-15Mo-xNb (with $\mathrm{x}=5 \%, 10 \%, 15 \%$, and $20 \%$ ) under dry condition state. The authors observed that enhancing the $\mathrm{Nb}$ content resulted in increase of the friction coefficient. The primary wear mechanism was observed to be adhesive wear in this work.

Ajithkumar et al. [7] investigated the dry sliding behavior of pure $\mathrm{Mg}$, hypereutectic, and hypoeutectic $\mathrm{Mg}$-Si alloys manufactured with the help of gravity casting technique. From their observations the authors reported that due to morphology change of primary $\mathrm{Mg}_{2} \mathrm{Si}$ from polyhedral to coarse dendrite the wear resistance of hypereutectic $\mathrm{Mg}-\mathrm{Si}$ alloys is greater compared to hypoeutectic alloys.

According to ASTM E23, Charpy impact test determines the amount of energy absorbed by a standard sample during fracture [8]. The fracture energy absorbed is a measure of the material's notch toughness and acts as a tool to study temperature-dependent ductile-brittle transition. This technique is extensively used in the industrial field, owing to its simplicity of experimentation. Another advantage of the method is results can be obtained rapidly and economically. The major limitation is some results are only comparative. The apparatus consists of a pendulum of known mass and length that is dropped from a known height to impact a notched specimen of material.

The impact test results are affected by a notch in the sample and thus it is required for the notch to be of regular dimensions and geometry [9]. The sample size also significantly affects the results since the dimensions determine whether or not the material is in plane strain. Amardeepak et al. studied the effect of variation of alloying elements on the hardness and impact strength characteristics of aluminium alloy A16463. The results of the experiments showed that the highest impact strength was obtained for the specimens having $0.750 \% \mathrm{Mg}$ and $0.2 \% \mathrm{Si}$ compositions of the alloy Al6463. Highest hardness values were obtained for specimens having $0.5 \% \mathrm{Mg}$, $0.875 \% \mathrm{Mg}$, and $0.575 \% \mathrm{Si}$ compositions of the aluminium alloy Al6463.

Nearly about four decades ago, the main prerequisite for the usage of the verification specimens was added to the standard for impact testing of metals, American Society for Testing and Materials (ASTM) Standard E 23. This happened because the metals impact testing community discovered that by conducting verification tests of impact machine performance using reference specimens were able to detect certain energy loss mechanisms which otherwise could not be observed during traditional physics-based measurements of machine performance (pendulum period, mass, mechanical friction, etc.) [10, 11].

Abouei et al. [12] studied the effect of Fe-rich intermetallic on the wear behavior of eutectic Al-Si alloy (LM13). The wear rate of the eutectic Al-Si alloy, 1.2Fe (addition of $1.2 \% \mathrm{Fe}$ to the eutectic Al-Si alloy, 1.2FeMn alloys (addition of Mn to the $1.2 \mathrm{Fe}$ alloy) at different applied loads was calculated. The results showed that $1.2 \mathrm{FeMn}$ alloy had the highest wear rate compared to other alloys at all applied loads. Mamatha et al. [13] addressed thermal effect, viscosity variation in tribological Squeeze film with Reynolds's equation. The load effect between two moving surfaces minimizes wear and reduces energy loss, friction between them.

Subramanian and Senthilkumar [14] evaluated the mechanical properties of aluminium alloy LM25 matrix reinforced with fused silica- $\mathrm{SiO}_{2}$ particulates (metal matrix composite). The composites were cast by stir casting route.
The results indicated an improvement in mechanical properties such as tensile strength, hardness, and impact strength due to the addition of $\mathrm{SiO}_{2}$ particulates as the reinforcement. Amardeepak et al. [15] studied the compression and hardness characteristics of aluminium alloy Al7068 by varying the $\mathrm{Mg}$ and $\mathrm{Zn}$ compositions. The results showed that the lowest strain was obtained for the specimens with $2.5 \% \mathrm{Mg}$ and $7.6 \% \mathrm{Zn}$ compositions and highest hardness for specimens with $3 \% \mathrm{Mg}$ and $8 \% \mathrm{Zn}$ compositions of the alloy A17068.

Murthy and Rao [16] studied the impact on mechanical properties of hybrid aluminium metal matrix composites fabricated by stir casting technique. The reinforcements aluminium oxide $\left(\mathrm{Al}_{2} \mathrm{O}_{3}\right)$, silicon carbide $(\mathrm{SiC})$ and boron carbide $\left(\mathrm{B}_{4} \mathrm{C}\right)$ were varied in different proportions in the base alloy matrix A16061. Mechanical tests such as tensile, flexural, charpy impact, and brinell hardness tests were conducted on the fabricated composites. The results showed that the variation of reinforcement proportion in the alloy had a significant impact on the mechanical properties of the hybrid composite.

Narasimma et al. [17] studied the artificial aging effect on mechanical properties and wear behavior of Aluminium LM4 alloys. The specimens were prepared as per ASTM standards for wear, hardness and tensile tests. The results of the investigation showed that with the increase in aging time hardness and tensile strength increased. Increase in hardness, applied load and aging time resulted in decreased rates of wear. Periasamy et al. [18] studied the effect on friction and wear by addition of (10\% wt. of $\mathrm{SiC})$ and (10\% wt. of Graphite) as the reinforcement by Friction Stir Processing method. Using SEM and EDS analysis the distribution of reinforcement was observed. The results of the investigation showed improved tribological and mechanical properties of the composite compared to the base metal aluminium alloy Al7075.

Prasad and Ramachandra [19] investigated the influence of process parameters such as squeeze pressure and reinforcement content on the tribological behavior and mechanical properties of squeeze cast LM6 Al-flyash composite. The reinforcement added to aluminium metal matrix composite was flyash (5-12.5\% wt.). The experimental results showed improved wear resistance of the composite compared to the base alloy. The examination of the microstucture revealed uniform distribution of the reinforcement (flyash particles) in the aluminium metal matrix. Wahab et al. [20] carried out preparation and characterization of reinforced aluminium nitide in aluminium metal matrix composites. The samples were prepared by using a graphite crucible and a stainless steel permanent mould. Optical microscopy technique was employed to observe the particle distribution in the composite [21]. The results of the investigation showed that increase in the hardness of the aluminium metal matrix was due to the addition of AIN (aluminium nitride) as reinforcement particles.

\section{EXPERIMENTATION}

The aluminium alloy was cast using the basic composition with a variation in the composition of the two major alloying elements that have a significant effect on the properties of the alloy. Magnesium percentage was varied from $2.2 \%$ to $3 \%$ and the zinc percentage from $7.3 \%$ to $8.3 \%$. The specimens for the wear and impact tests were prepared as per the ASTM standard and experimentation conducted [22, 23]. The chemical composition of Al7068 is shown in Table 1. 
Table 1. Chemical composition of A17068 aluminium alloy in weight percentage

\begin{tabular}{ccccccccc}
\hline Weight \% & Al & Si & Fe & Cu & Zr & Mg & Zn & Others each \\
\hline 7068 & Bal & $<0.12$ & $<0.15$ & $1.6-2.4$ & $0.05-0.15$ & $2.2-3$ & $7.3-8.3$ & $0.05-0.12$ \\
\hline
\end{tabular}

\subsection{Wear test}

The wear test was conducted by using Ducom pin-on-disc apparatus as shown in Figure 1 and the wear rate calculated. The test was conducted as per the ASTM Standard Code ASTM G99 - 17 which is the standard test method for Wear testing. The specimen dimensions were length $50 \mathrm{~mm}$ and diameter $9 \mathrm{~mm}$ with a constant track radius of $60 \mathrm{~mm}$. The speed was maintained constant at $1000 \mathrm{rpm}$ and time was set to 180 seconds. The loads were varied from 1,2 , and $3 \mathrm{Kg}$ respectively and the Frictional force values noted down.

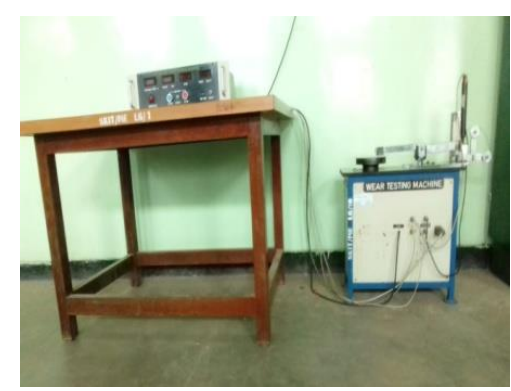

Figure 1. Ducom pin-on-disc apparatus for wear test

\subsubsection{Wear test apparatus}

Tables $2 \& 3$ give the experimental details of wear test of the aluminium alloy Al7068 by varying the magnesium and zinc percentage composition. Figures 2 and 3 show the graphical representation of wear test results of aluminium alloy A17068 with $\mathrm{Mg}$ and $\mathrm{Zn} \%$ variation.

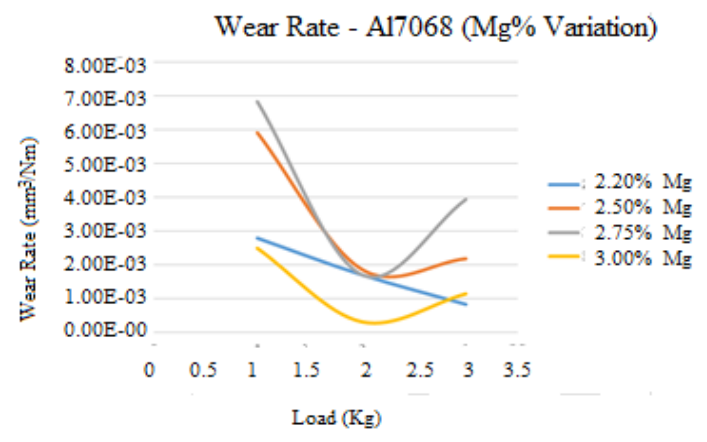

Figure 2. Graphical representation of wear test results for Al7068 specimens with $\mathrm{Mg} \%$ variation

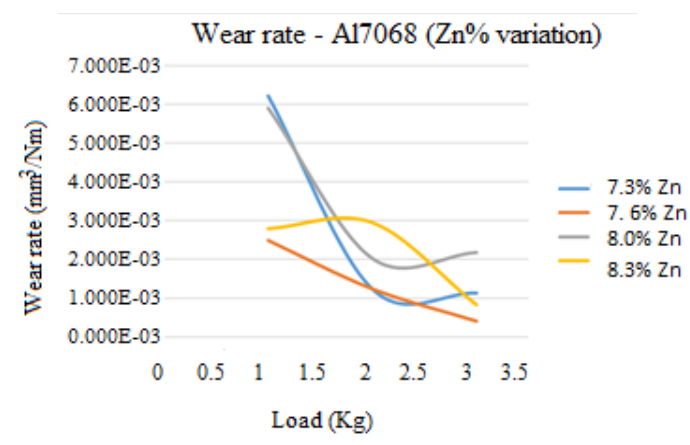

Figure 3. Graphical representation of wear test results for Al7068 specimens with $\mathrm{Zn} \%$ variation
Wear is defined as accelerated loss of material from the operating surfaces as a result of relative motion and is calculated by the difference of initial and final weights of the specimen. It is generally expressed as grams ( $\mathrm{g}$ ) or milligrams $(\mathrm{mg})$ and can be converted into volume loss by considering its density. It can be computed by using these formulae with the help of various parameters.

Let, $V_{l}$ be the Volume loss/Volume of material removed $\left(\mathrm{mm}^{3}\right)$, then it is defined as:

$$
V_{l}=\frac{W e i g h t \operatorname{loss}(g)}{\operatorname{Density}\left(\mathrm{g} / \mathrm{mm}^{3}\right)}
$$

Wear rate is calculated by Volume loss method using the formula:

$$
\text { Wear Rate }=\frac{\text { Volume of material removed }\left(\mathrm{mm}^{3}\right)}{\text { Frictional force } * \text { Sliding Distance }(N-m)}
$$

\subsection{Impact test}

The Charpy impact test apparatus IT-30(ASTM) was used in the present work as shown in Figure 4(a). The test was performed in compliance with ASTM E23 standard on a specimen of size $10 \mathrm{~mm} \times 10 \mathrm{~mm} \times 55 \mathrm{~mm}$ with a notch of dimensions $2 \mathrm{~mm} \times 2 \mathrm{~mm} \times 45^{\circ}$ as shown in Figure 4(b) and the impact energy absorbed by the specimen was recorded.

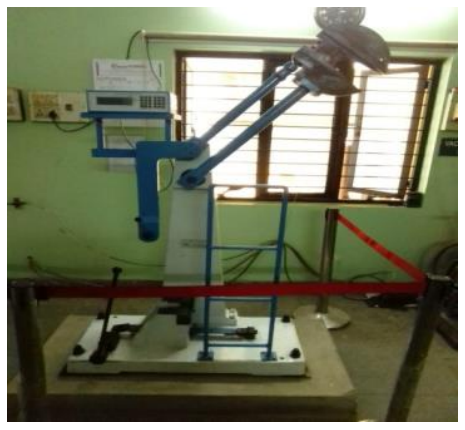

(a)

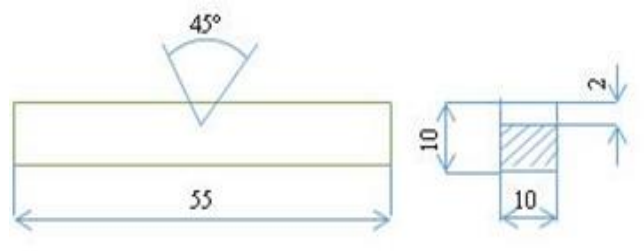

All dimensions are in rmm.

(b)

Figure 4. (a) Charpy impact test apparatus IT-30 (ASTM); (b) Impact test specimen ASTM E-23 Standard

\section{RESULTS AND DISCUSSIONS}

\subsection{Wear test}

Table 2 shows the experimental results for wear test 
conducted on the aluminium alloy $\mathrm{A} 17068$ with $\mathrm{Mg} \%$ variation. Figure 2 shows the graphical representation of the experimental values shown in Table 2. It shows that the specimen with a composition of $2.75 \% \mathrm{Mg}$ gives the highest wear rate compared to other specimens at a low load of $1 \mathrm{~kg}$. Also, it indicates that the specimen with $3 \% \mathrm{Mg}$ gives the least wear at a load of $2 \mathrm{~kg}$. The wear rate of the specimen with $3 \%$ $\mathrm{Mg}$ composition decreases by $87.5 \%$ as the load is increased from $1 \mathrm{~kg}$ to $2 \mathrm{~kg}$ with an increase by $33.47 \%$ as the load is further increased to $3 \mathrm{~kg}$. This shows that higher composition of Magnesium in the aluminium alloy A17068 gives the least wear at moderate loads.
Table 3 shows wear test results of aluminium alloy Al7068 with $\mathrm{Zn} \%$ variation. Figure 3 shows the graphical representation of the experimental values shown in Table 3. It shows the specimen with $7.3 \% \mathrm{Zn}$ composition gives the highest wear rate compared to other specimens at a low load of $1 \mathrm{~kg}$. Also, it indicates that the specimen with $7.6 \% \mathrm{Zn}$ has the least wear rate at a high load of $3 \mathrm{~kg}$. The wear rate of the specimen with $7.6 \% \mathrm{Zn}$ composition decreases by $50 \%$ as the load is increased from $1 \mathrm{~kg}$ to $2 \mathrm{~kg}$ with a further decrease by $33.33 \%$ with the increase in load to $3 \mathrm{~kg}$. This indicates that the lower composition of Zinc in the aluminium alloy Al7068 gives the least wear at higher loads.

Table 2. Wear test results for Al7068 specimens with $\mathrm{Mg} \%$ variation

\begin{tabular}{ccccc}
\hline Specimen (Mg\%) & Load(kg) & Initial Weight $(\mathbf{g})$ & Final Weight $(\mathbf{g})$ & Wear Rate( $\mathbf{m m} \mathbf{3} / \mathbf{N m})$ \\
\hline \multirow{2}{*}{$2.200 \%$} & 1 & 8.750 & 8.741 & $2.79 \mathrm{E}-03$ \\
& 2 & 8.741 & 8.730 & $1.71 \mathrm{E}-03$ \\
$2.500 \%$ & 3 & 8.730 & 8.722 & $8.27 \mathrm{E}-04$ \\
\hline \multirow{2}{*}{$2.750 \%$} & 1 & 8.612 & 8.593 & $5.89 \mathrm{E}-03$ \\
& 2 & 8.593 & 8.581 & $1.86 \mathrm{E}-03$ \\
& 3 & 8.581 & 8.560 & $2.17 \mathrm{E}-03$ \\
\hline \multirow{3}{*}{$3.000 \%$} & 1 & 8.345 & 8.323 & $6.83 \mathrm{E}-03$ \\
& 2 & 8.323 & 8.312 & $1.71 \mathrm{E}-03$ \\
& 3 & 8.312 & 8.274 & $3.93 \mathrm{E}-03$ \\
\hline & 1 & 8.792 & 8.784 & $2.48 \mathrm{E}-03$ \\
& 2 & 8.789 & 8.787 & $3.10 \mathrm{E}-04$ \\
& 3 & 8.787 & 8.776 & $1.14 \mathrm{E}-03$ \\
\hline
\end{tabular}

Table 3. Wear test results for Al7068 specimens with $\mathrm{Zn} \%$ variation

\begin{tabular}{|c|c|c|c|c|}
\hline Specimen (Zn\%) & Load(kg) & Initial weight $(\mathrm{g})$ & Final weight(g) & Wear Rate $\left(\mathrm{mm}^{3} / \mathrm{Nm}\right)$ \\
\hline \multirow{3}{*}{$7.300 \%$} & 1 & 8.425 & 8.405 & $6.205 \mathrm{E}-03$ \\
\hline & 2 & 8.405 & 8.397 & $1.241 \mathrm{E}-03$ \\
\hline & 3 & 8.397 & 8.386 & $1.138 \mathrm{E}-03$ \\
\hline \multirow{3}{*}{$7.600 \%$} & 1 & 9.161 & 9.153 & $2.482 \mathrm{E}-03$ \\
\hline & 2 & 9.153 & 9.145 & $1.241 \mathrm{E}-03$ \\
\hline & 3 & 9.145 & 9.141 & 4.137E-04 \\
\hline \multirow{3}{*}{$8.000 \%$} & 1 & 8.757 & 8.738 & $5.895 \mathrm{E}-03$ \\
\hline & 2 & 8.738 & 8.725 & 2.017E-03 \\
\hline & 3 & 8.725 & 8.704 & $2.172 \mathrm{E}-03$ \\
\hline \multirow{3}{*}{$8.300 \%$} & 1 & 8.623 & 8.614 & 2.792E-03 \\
\hline & 2 & 8.614 & 8.595 & $2.947 \mathrm{E}-03$ \\
\hline & 3 & 8.595 & 8.587 & $8.273 \mathrm{E}-04$ \\
\hline
\end{tabular}

\subsection{Impact test}

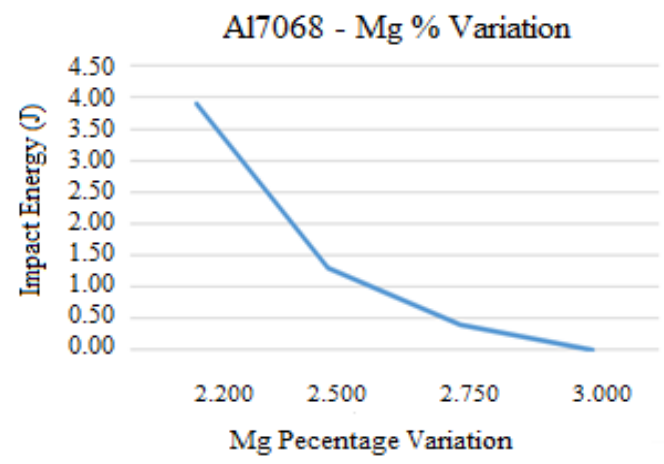

Figure 5. Graphical representation of impact test results for Al7068 specimens with $\mathrm{Mg} \%$ variation

Table 4 gives the impact test results of Al7068 with $\mathrm{Mg} \%$ variation and Figure 5 graphical representation of the experimental values shown in Table 4. The impact test conducted on the alloy $\mathrm{Al} 7068$ with $\mathrm{Mg} \%$ variation shows that the lowest composition of $2.2 \% \mathrm{Mg}$ gives the highest impact energy absorbed of 3.9J. The impact energy decreases by $66.7 \%$ for composition varying from 2.2 to $2.5 \% \mathrm{Mg}$ which further decreases by $23 \%$ for composition varying from 2.5 to $2.75 \% \mathrm{Mg}$. For the composition varying from 2.75 to $3 \% \mathrm{Mg}$, the impact of energy again decreases by $10.3 \%$. This indicates that $2.2 \% \mathrm{Mg}$ specimen of the aluminium alloy Al7068 exhibits better impact strength compared to other specimens.

Table 5 gives the impact test results of Al7068 with $\mathrm{Zn} \%$ variation and Figure 6 graphical representation of the experimental values shown in Table 5 .

Table 4. Impact test results for A17068 specimens with $\mathrm{Mg} \%$ variation

\begin{tabular}{ccc}
\hline Specimen & \% Mg & Impact Energy (J) \\
\hline Mg1 & 2.200 & 3.90 \\
Mg2 & 2.500 & 1.30 \\
Mg3 & 2.750 & 0.40 \\
Mg4 & 3.000 & 0.00 \\
\hline
\end{tabular}


Table 5. Impact test results for Al7068 specimens with $\mathrm{Zn} \%$ variation

\begin{tabular}{ccc}
\hline Specimen & \%Zn & Impact Energy (J) \\
\hline Zn1 & 7.300 & 0.20 \\
Zn2 & 7.600 & 1.20 \\
Zn3 & 8.000 & 0.20 \\
Zn4 & 8.300 & 0.40 \\
\hline
\end{tabular}

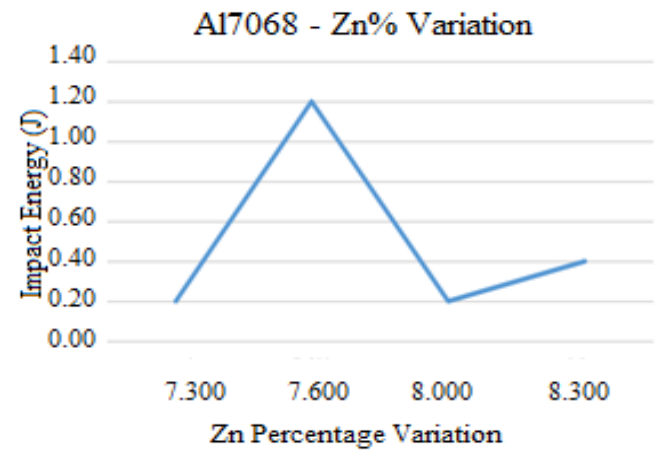

Figure 6. Graphical representation of impact test results for Al7068 specimens with $\mathrm{Zn} \%$ variation

The impact test conducted on the alloy Al7068 with $\mathrm{Zn} \%$ variation shows that the composition of $7.6 \%$ gives the highest impact energy absorbed of 1.2J. The impact energy increases by $83.3 \%$ for $\mathrm{Zn}$ composition varying from 7.3 to $7.6 \% \mathrm{Zn}$ with a decrease in impact energy by $83.3 \%$ for composition varying from 7.6 to $8 \% \mathrm{Zn}$. Further increase in composition from 8 to $8.3 \% \mathrm{Zn}$ increases the impact energy by $16.7 \%$. This indicates that the specimen with $7.6 \% \mathrm{Zn}$ composition of the aluminium alloy A17068 gives the highest impact strength compared to other specimens.

\section{CONCLUSIONS}

The wear and impact tests were conducted as per ASTM standards on the aluminium alloy Al7068 to study the tribological behavior and impact strength by varying the percentage composition of the two major alloying elements $\mathrm{Mg}$ and $\mathrm{Zn}$ in the alloy. The specimens were prepared as per the standards for the tests and experimentation conducted. It is observed that variation in the composition of the two alloying elements $\mathrm{Mg}$ and $\mathrm{Zn}$ has a significant influence on the wear rate and impact strength of the alloy A17068. The following conclusions can be drawn from the experimental values obtained from the tests.

$>$ The results of wear test for Al7068 alloy with $\mathrm{Mg} \%$ composition varying shows that the specimen of $3 \% \mathrm{Mg}$ gives least wear compared to other specimens at a load value of $2 \mathrm{~kg}$ which indicates that applications requiring lower rates of wear need to have a high composition of Magnesium at moderate loads.

$>\quad$ The results of wear test for Al7068 alloy with Zn\% composition varying shows that the specimen of $7.6 \% \mathrm{Zn}$ gives least wear compared to other specimens at a high load value of $3 \mathrm{~kg}$ which means that applications requiring lower wear rates need to have a low composition of Zinc at higher loads.

$>$ The impact test conducted on the alloy Al7068 with $\mathrm{Mg} \%$ composition varying shows that the specimen of
$2.2 \% \mathrm{Mg}$ composition gives the highest impact energy absorbed of 3.9J which indicates that the low percentage composition of magnesium increases the impact strength of the alloy and hence improves its performance.

$>\quad$ The impact test conducted on the alloy A17068 with varying $\mathrm{Zn} \%$ composition shows that the specimen of 7.6\% Zn composition gives the highest impact energy absorbed of 1.2J. This indicates that the low percentage composition of $\mathrm{Zn}$ increases the impact strength of the alloy and in turn improves its performance.

\section{REFERENCES}

[1] Goode, P.D. (1989). Wear mechanisms in ferrous alloys. Nuclear Instruments and Methods in Physics Research Section B: Beam Interactions with Materials and Atoms, 39(1-4): $\quad 521-530 . \quad$ https://doi.org/10.1016/0168583X(89)90839-2

[2] Choubey, A., Basu, B., Balasubramaniam, R. (2004). Tribological behaviour of Ti-based alloys in simulated body fluid solution at fretting contacts. Materials Science and Engineering: A, 379(1-2): 234-239. https://doi.org/10.1016/j.msea.2004.02.027

[3] Li, S.J., Yang, R., Li, S., Hao, Y.L., Cui, Y.Y., Ninomi, M., Guo, Z.X. (2004). Wear characteristics of Ti-Nb-Ta$\mathrm{Zr}$ and Ti-6Al-4V alloys for biomedical applications. Wear 2004, 257(9-10): 869-876. https://doi.org/10.1016/j.wear.2004.04.001

[4] Chiba, A., Kumagai, K., Nomura, N., Miyakawa, S. (2007). Pin-on-disk wear behavior in a like-on-like configuration in a biological environment of high carbon cast and low carbon forged $\mathrm{Co}-29 \mathrm{Cr}-6 \mathrm{Mo}$ alloys. ActaMaterialia, 55(4): 1309-1318. https://doi.org/10.1016/j.actamat.2006.10.005

[5] Fischer, A., Weiß, S., Wimmer, M.A. (2012). The tribological difference between biomedical steels and Co-Cr-Mo-alloys. Journal of the Mechanical Behavior of Biomedical Materials, 9: 50-62. https://doi.org/10.1016/j.jmbbm.2012.01.007

[6] Xu, L., Xiao, S., Tian, J., Chen, Y. (2013). Microstructure, mechanical properties, and dry wear resistance of $\beta$-type Ti-15Mo-xNb alloys for biomedical applications. Transactions of Nonferrous Metals Society of China, 23(3): 692-698. https://doi.org/10.1016/S10036326(13)62518-2

[7] Ajith Kumar, K.K., Pillai, U.T.S., Pai, B.C., Chakraborty, M. (2013). Dry sliding wear behaviour of Mg-Si alloys. Wear, 303(1-2): 56-64. https://doi.org/10.1016/j.wear.2013.02.020

[8] Garcia, A., Spim, J.A., dos Santos, C.A. (2000). Ensaios dos materiais. LivrosTécnicos e científicos.

[9] Kurishita, H., Kayano, H., Narui, M., Yamazaki, M., Kano, Y., Shibahara, I. (1993). Effects of V-notch dimensions on Charpy impact test results for differently sized miniature specimens of ferritic steel. Materials Transactions - JIM. Japan Institute of Metals, 34(11): 1042-1052. https://doi.org/10.2320/matertrans1989.34.1042

[10] Amardeepak, M., Doddapattar, N.B., Murthy, S. (2020). Effect of variation of alloying elements on hardness and impact strength characteristics and application of the Taguchi technique for optimization of drilling parameters of aluminium alloy Al6463. I-manager's 
Journal on Mechanical Engineering, 10(1): 41-50. https://doi.org/10.26634/jme.10.1.16841

[11] ASTM Standard E23. Standard Test Methods for Notched Bar Impact Testing of Metallic Materials.03.01. American Society for Testing and Materials; Conshohocken, Pennsylvania: 1999.

[12] Abouei, V., Saghafian, H., Shabestari, S.G., Zarghami, M. (2010). Effect of Fe-rich inter metallics on the wear behavior of eutectic Al-Si piston alloy (LM13). Materials \& Design, 31(7): 3518-3524. https://doi.org/10.1016/j.matdes.2010.02.015

[13] Mamatha, E., Reddy, C.S., Sharma, R. (2018). Effects of viscosity variation and thermal effects in squeeze films. Annales de Chimie - Science des Matériaux, 42(1): 5774. https://doi.org/10.3166/ACSM.42.57-74

[14] Subramanian, T., Senthilkumar, N. (2019). Evaluation of mechanical properties of aluminium alloy (LM25) reinforced with fused silica metal matrix composite. Indian Journal of Engineering \& Material Sciences, 26(1): 59-66.

[15] Amardeepak, M., Doddapattar, N.B., Murthy, S. (2019). Experimental study on compression and hardness characteristics of aluminium alloy A17068. I-manager's Journal on Future Engineering \& Technology, 14(3): 4348. https://doi.org/10.26634/jfet.14.3.15174

[16] Murthy, S.R.P., Rao, S.R.Y. (2019). Impact on mechanical properties of hybrid aluminium metal matrix composites. International Journal of Engineering and Advanced Technology, 8(6): 1638-1645. https://doi.org/10.35940/ijeat.F8214.088619

[17] Narasimma, M.S., Ilangovan, S., Anbuudayasankar, S.P., Pavithran, P. (2019). Effect of reinforcement and aging time on wear behavior and mechanical properties of Aluminium LM4. International Journal of Engineering and Advanced Technology (IJEAT), 8(5): 2426-2433.

[18] Periasamy, K., Sivashankar, N., Chandrakumar, S., Viswanathan, R. (2020). Measurement of friction and wear in aluminium alloy $\mathrm{A} 17075 \mathrm{SiC} \& \mathrm{Gr}$ processed by friction stir method. International Journal of Innovative Technology and Exploring Engineering, 9(3): 278-281. https://doi.org/10.35940/ijitee.C8480.019320

[19] Prasad, K.N.P., Ramachandra, M. (2018). Detrmination of abrasive wear behavior of Al-flyash metal matrix composites produced by squeeze casting. Materials Today: Proceedings, 5(1): 2844-2853. https://doi.org/10.1016/j.matpr.2018.01.075

[20] Wahab, M.N., Daud, A.R., Ghazali, M.J. (2009). Preparation and characterization of stircast-aluminium nitride reinforced aluminium metal matrix composites. International Journal of Mechanical and Materials Engineering, 4(2): 115-117.

[21] Dyaneshwar, S.S., Manoj, S.A., Gangadhar, D.A., Balinge, K.R., Mana, A.P., Bhagat, P.R. (2019). Comparing the tribological properties of chloride-based and tetra fluoroborate-based ionic liquids. Annales de Chimie: Science des Matériaux, 43(5): 317-327. https://doi.org/10.18280/acsm.430507

[22] Kesavalu, R., Ramamoorthy, S. (2020). Experimental studies and finite element modeling on incrementally formed AZ61A magnesium alloy. Journal of New Materials for Electrochemical Systems, 23(1): 25-30. https://doi.org/10.14447/jnmes.v23i1.a05

[23] Younes, R., Bradai, M.A., Sadeddine, A., Mouadji, Y. (2020). Effect of bond-layer on the wear resistance of a martensitic stainless steel coating obtained by wire arc spray. Revue des Composites et des Matériaux AvancésJournal of Composite and Advanced Materials, 30(1): 29-34. https://doi.org/10.18280/rcma.300105 